\title{
Analysis of Outline Measurements Methods of Spur Gear Involute Profile
}

\author{
Piotr BORAL*, Rafal GOŁĘBSKI, Antun STOIĆ
}

\begin{abstract}
Comparsion of measuring methods for the involute profile of the spur gear tooth is described in this paper. The gear profile measurement results from the universal toolmakers microscope are compared with the results of use of Zeiss coordinate measuring machine with Gear Pro software and with the results of the theoretical calculation of the reference profile. The proposed measurements methods can be successfully used in quality management of unit production of gear drives.
\end{abstract}

Keywords: involute profile; spur gear; universal toolmakers microscope

\section{INTRODUCTION}

Nowadays, due to the increasing use of universal multi-axis CNC machines, there is a tendency to transfer gear production from special machine tools to $\mathrm{CNC}$ machine tools [1-5]. Similarly, for gear measurement, in place of special measuring machines, a universal toolmakers microscope can be used. Gear wheels with an involute profile still find wide application in many machines and devices, whereby there are numerous publications dealing with their toothing analysis and manufacturing technology $[6,7]$. The involute profile of a spur gear can be measured with an involute tester that is specially designed for this purpose, or on a coordinate measuring machine equipped with appropriate software [813]. The profile can also be verified by contactless methods using a computer scanning technology $[14,15]$. In many industrial applications, especially when there is a need for measuring the gear tooth profile in unit production, the involute tester, as well as the coordinate measuring machine with expansive software, might be unavailable, whereas the universal toolmaker's microscope is a basic measuring instrument being a part of the equipment of many metrological laboratories. Therefore, this article proposes an alternative method for measuring the involute profile of the spur gear tooth on the universal toolmakers microscope and its verification instead of the measurement method on a coordinate measuring machine.

\section{THE GEAR TOOTH PROFILE MEASURING METHOD 2.1 Measuring Using Universal Toolmakers Microscope}

First, it is necessary to construct a special template (fixing accessory) for setting the measuring tip of the attachment for measuring holes on the microscope-Fig. 1 . The template shall have an outer diameter equal to the diameter of the base cylinder of the gear to be measured, and a base surface for setting the measuring tip, therefore it must be made for each gear with a different diameter of the base cylinder.

$$
\frac{d_{\mathrm{b}}}{2}=z m \cos \alpha
$$

where: $d_{\mathrm{b}}$ - gear base cylinder diameter, $z$ - number of teeth, $m$ - module, $\alpha$-profile angle.
The sensor is a hole measuring attachment being part of the microscope's equipment. The template allows the measuring tip to be set in the starting position at the initial involute gear tooth profile point on the base cylinder in the axial plane of the gear to be measured.

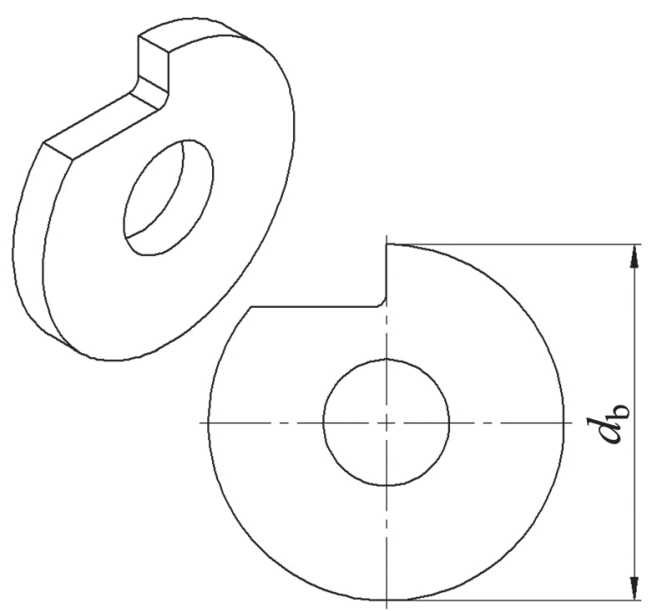

Figure 1 Measuring tip setting template

The template and the measured gear are mounted on the same shaft on the measuring table, with the capability of being rotated with an optical dividing attachment (the shaft is fixed in the centres of the dividing head and the tailstock. The hole measuring attachment is mounted on the microscope's vertical column - Fig. 2.

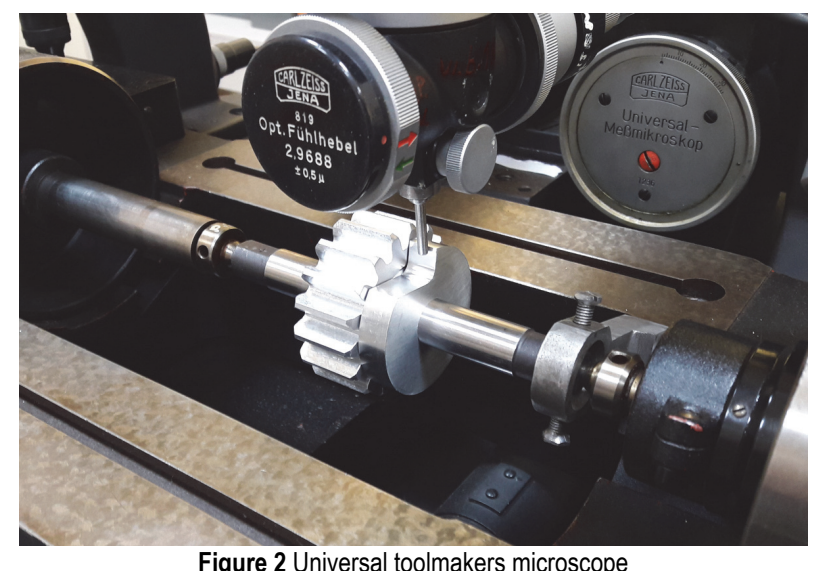

The setting of the measuring tip involves moving it along the template base surface (by rotating the template 
and moving the tip along the template base surface) in the gear axial plane. As the measuring tip moves along the sensor base surface in the $Z$ axis, initially (at any angular template setting) three short double marks and one long mark move relative to one another in the sensor's field of vision. By rotating the template (using the dividing head) and moving the measuring sensor towards the $Z$ axis, bring about a situation where the long mark (the eyepiece's centre line) in the sensor's field of vision is encompassed by three short marks, and their relative position is unchanged.

Then, by moving the measuring tip in the $Z$ axis along the template base surface (with no template rotation), determine the point at which the tip is positioned on the template outer diameter (i.e. the point at which the relative displacement of the sensor's eyepiece centre line and the three double marks starts). By moving the measuring table towards the $X$ axis (i.e. in the centres axis direction), introduce the measuring tip into the region of the measured gear's inter-tooth zone, and then, by rotating the gear with the dividing head, bring the tip in contact with the gear tooth flank (in the sensor eyepiece, the centre line is in the middle between the double marks). Thus, the involute profile starting point and its coordinates are determined Fig. 3.

$$
1\left[0, \quad y_{1}, \frac{d_{\mathrm{b}}}{2}, \varphi_{1}\right]
$$

where: 1 - number (index) of the next (measured) gear tooth profile point, $y_{1}$ - coordinate of transverse table displacement for the profile point defined by the index, $\varphi_{1}$ - gear rotation angle (measured point radius vector angle) read out on the dividing head (the index identifies the point).

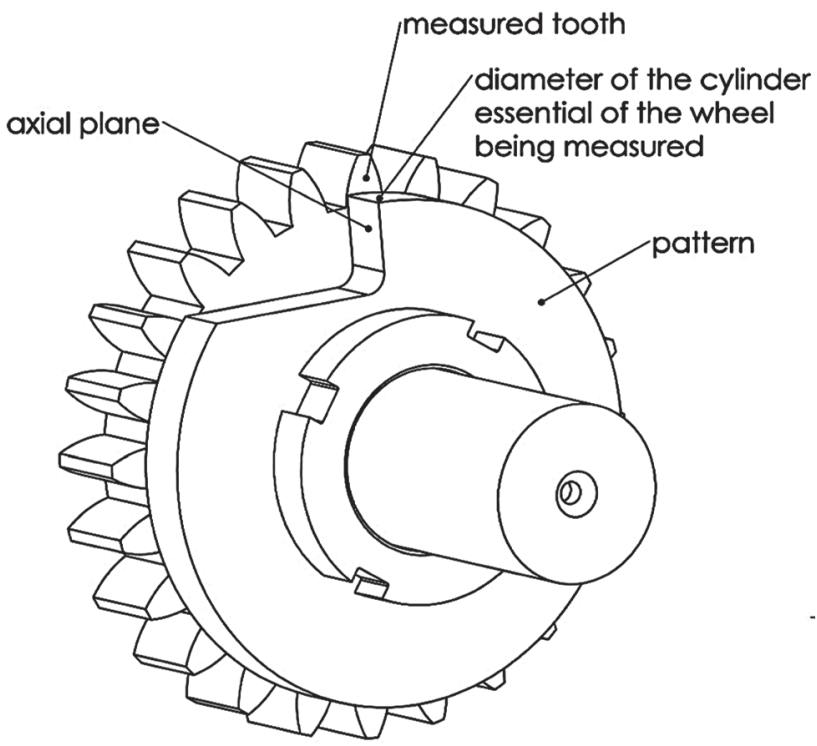

Figure 3 Schematic diagram of template setting relative to the measured gear tooth profile

The first coordinate defines the position of the profile in the $X$ axis and can be read out from the micrometre screw of longitudinal microscope table displacement; yet, taking account of the fact that the measurement is taking place in a fixed plane, a zero value of this coordinate can be assumed. The second coordinate corresponds to the microscope measuring table position in the lateral direction in the $Y$ axis, and is read out from the micrometre screw of microscope table displacement. The third coordinate corresponds to the measuring tip setting on the gear's base cylinder diameter, and this value will be constant for all gear tooth profile points, as follows from the adopted gear tooth profile measurement method. The last coordinate is read out from the optical dividing attachment and defines the angular position of the gear for a given measured profile point (defined by the index number). To determine the next profile point, rotate the gear by a specified angle using the dividing head. Then, moving the measuring table in the transverse direction (in the $Y$ axis), bring the gear to a position in which the measuring tip contacts the profile in the gear axial plane - Fig. 4. In this way you can determine the coordinates for several points of the gear tooth outline.

$$
i\left[0, \quad y_{i}, \frac{d_{\mathrm{b}}}{2}, \quad \varphi_{i}\right] i \in<1, \ldots, n>
$$

where: $i$ - number (index) of the next (measured) gear tooth profile point, $n$ - number of measurement points, $y_{1}$ coordinate of transverse table displacement for the profile point defined by the index, $\varphi_{1}$ - gear rotation angle (measured point radius vector angle) read out on the dividing head (the index identifies the point)

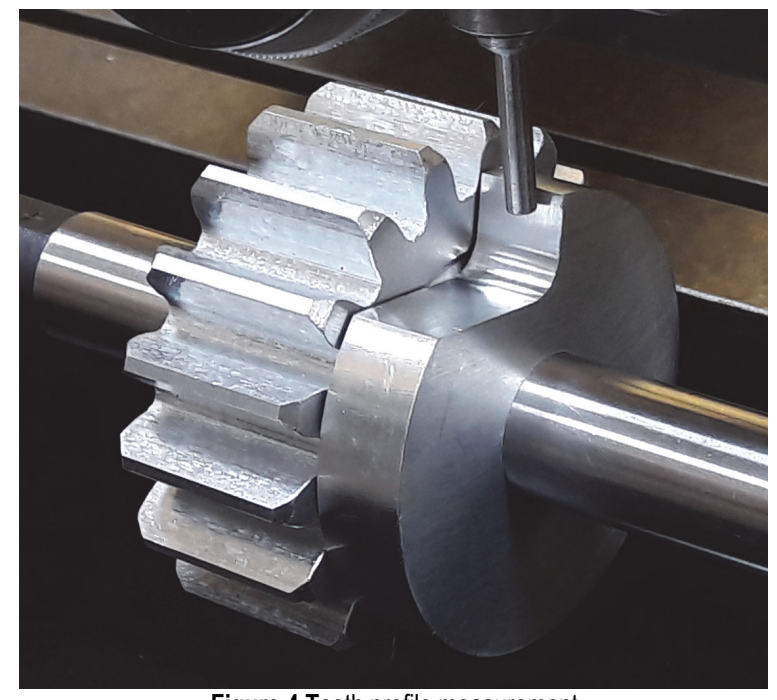

Figure 4 Tooth profile measurement

If we assume that the angle $\varphi_{1}$ is defined as the difference between the angle read out from the optical dividing head for a point with index 1 and points with index $i$, then we can write (in the computation program) as follows:

$$
\varphi_{i}=\varphi_{i}-\varphi_{1}, \varphi_{1}=0
$$

This will facilitate the comparison of the gear tooth profile measurement results with the theoretical involute profile. As follows from the described measurement method, the sensor is not moved in the $Z$ axis for successive measurement point, which means that the $Z$ coordinate for profile points does not change. What only changes for 
successive measurement points are the coordinates in the $Y$ axis direction and the gear rotation angles.

The radius to the measured profile point is equal to

$r_{i}=\sqrt{\left(y_{i}\right)^{2}+\left(\frac{d_{\mathrm{b}}}{2}\right)^{2}}$

The coordinates of the profile point of the reference (theoretical) gear involute are equal to - Fig. 5.

$$
\begin{aligned}
& \left(x_{\mathrm{e}}\right)_{i}=\frac{d_{\mathrm{b}}}{2}\left(\sin \varphi_{i}-\varphi_{i} \cos \varphi_{i}\right) \\
& \left(y_{\mathrm{e}}\right)_{i}=\frac{d_{\mathrm{b}}}{2}\left(\cos \varphi_{i}+\varphi_{i} \sin \varphi_{i}\right)
\end{aligned}
$$

These coordinates (6) describe the involute in the system of coordinates with the axis of ordinates passing through the first profile point lying on the base cylinder of the gear. After considering relationship (4) for the profile being measured, the measured profile will be represented in the same system of coordinates, and the angles assumed in relationship (6) will enable the determination of the coordinates of the reference profile (theoretical involute) for the measurement points.

The radii of the subsequent points on the reference involute profile are equal to

$$
\left(r_{\mathrm{e}}\right)_{i}=\sqrt{\left(x_{\mathrm{e}}\right)_{i}^{2}+\left(y_{\mathrm{e}}\right)_{i}^{2}}
$$

where: $\left(r_{\mathrm{e}}\right)_{i}$ - radius vectors of reference involute profile points (index $e$ ) defined by the index $i$.

Taking into account the fact that during measurement the gauging point will always be at the same level relative to the measured gear axis, being equal to $d_{\mathrm{b}} / 2$, the value of the radius $r_{\mathrm{e}}$ is theoretically defined by the formula:

$$
\left(r_{\mathrm{e}}\right)_{i}=\frac{d_{\mathrm{b}}}{2 \cos \left(\varphi_{i}+\operatorname{inv} \varphi_{i}\right)}
$$

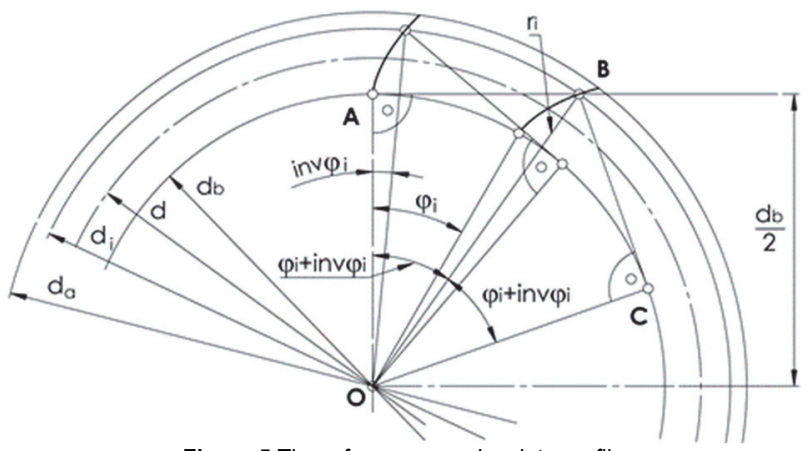

Figure 5 The reference gear involute profile

Profile errors can be defined as the differences between the measured profile radii and the reference profile points - Fig. 6 .

$\delta_{i}=r_{i}-\left(r_{e}\right)_{i}$

where: $\delta_{i}$ - involute profile errors defined by the index $i$.

\subsection{Measuring Using Coordinate Measuring Machine with ZEISS GEAR PRO Software}

A Zeiss coordinate measuring machine was used for the measurement along with specialized Gear Pro measuring software. At the beginning, the program defines the parameters of the measured wheel such as the number of teeth, module, profile angle and tooth thickness modification factor. Other parameters are automatically calculated by the program. If the data is given correctly, the program will generate a solid model of the measured object. After defining the measured element, it is necessary to develop a measurement plan. The following parameters have been checked: tooth profile, tooth line, gear pitch, tooth thickness.

The program allows you to freely interfere with the measured area. First you can choose the measured range, which eliminates thick errors that may be at the ends of the profile. In the program, an additional very useful option is to enter the profile correction for the measured wheel.

All basic parameters of the tested gear wheel were measured. Only the profile deviation from involute was selected for analysis as part of the study.

\section{MEASUREMENTS RESULTS}

In order to verify the correctness of the discussion of the presented involute tooth profile measurement method, the profile of a gear of a module of $m=3$ and $z-17$ was measured. The obtained deviations of the profile from the involute are illustrated in Fig. 6.

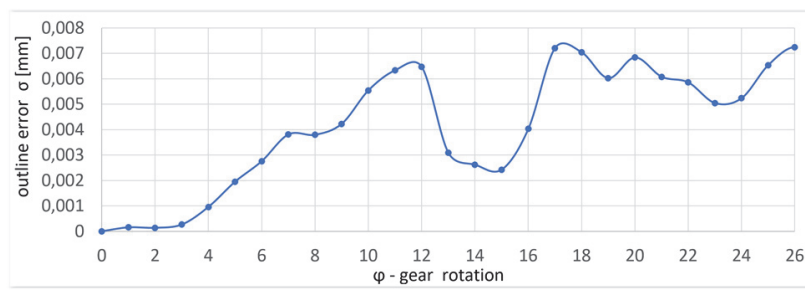

Figure 6 The result of gear tooth profile measurement done on the tools maker microscope. Distribution of the deviation over the diameter from calculated involute profile in the function of gear rotation angle.

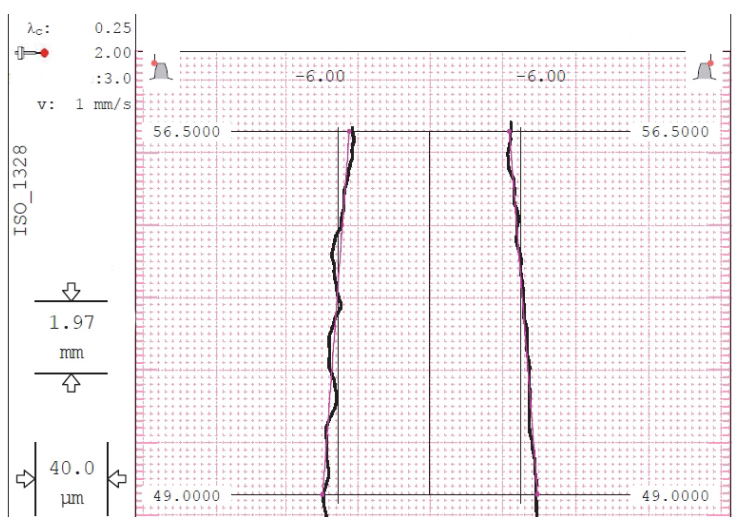

Figure 7 The result of gear tooth profile measurement done on the Zeiss coordinate measuring machine using the Gear Pro software. Distribution of the deviation over the diameter from calculated involute profile.

For comparison, the same gear was measured on a Zeiss coordinate measuring machine using the GEAR PRO software. In this case, it is sufficient to limit the data entered in the program to the following: the module, the 
number of teeth, correction coefficient, profile angle, rim width and the angle of tooth line inclination. The measurement results are shown in Fig. 7.

The results of microscopic profile measurements are discrete in character, while the results of measurements done on the measuring machine are obtained in the form of a continuous graph. This, in a sense, limits the form of provided comparison results only to general conclusions. Obviously, the obtained results can be converted from the discrete form - as a function of the gear rotation angle to the Cartesian coordinate system. Nevertheless, the obtained results confirm the correctness and efficiency of determining the involute spur gear profile on the universal toolmaker's microscope, as shown by the small differences between measurement results (whereas, allowance should be made for the gear tolerance class and profile tolerance). For the proposed measurement method to be considered correct, the differences should be contained within tolerance range.

\section{CONCLUSION}

After a comparative analysis of the measurement on a toolmakers microscope and using a coordinate measuring machine with Gear Pro software, we can conclude that the measurement methodology described in the work gives valuable data. Measurement of the tooth involute profile is not simple. In this case the results are obtained in the form of a discrete set of points, the number of which can be selected randomly and nevertheless allow the selection of any measurement resolution. The results obtained with this alternative method are in line with the profile measurement results obtained on the coordinate measuring machine and are within the tolerance of the involute profile for a given wheel accuracy class. The measurement results may also be affected by the prisms of the tooth surface resulting from the wheel machining method. The presented method of measurement can be an excellent alternative in the case of measuring the gear profile in unit production and can replace the measurement of the outline on a coordinate measuring machine with specialized software, which may be difficult to access due to the high cost and, in particular, the unusual size of the tested gear. The disadvantage of the proposed method is the lack of universality of the template used. Its outer diameter must be equal to the diameter of the base cylinder of the gear and therefore it must be made for each gear with a different diameter of the base cylinder. The method can be used to measure cylindrical gears with various outline types.

\section{REFERENCES}

[1] Boral, P. (2018). Technological determinants of the teething geometry of worm gears with either a fixed or variable pitch worm. Czestochowa University Publish House.

[2] Nieszporek, T. \& Boral, P. (2017). Examination of the cylindrical worm profile. MATEC Web of Conferences, 94. https://doi.org/10.1051/matecconf/20179407007

[3] Nieszporek, T., Boral, P., \& Gołębski, R. (2017). An Analysis of Gearing. MATEC Web of Conferences, 94. https://doi.org/10.1051/matecconf/20179407006

[4] Nieszporek, T., Gołębski, R., \& Boral, P. (2017). Shaping the Helical Surface by the Hobbing Method. Procedia Engineering, 177, 49-56. https://doi.org/10.1016/j.proeng.2017.02.181

[5] Gołębski, R. \& Željko, I. (2017), Analysis of Modification of Spur Gear Profile. Technical Gazette, 25(2), 643-648. https://doi.org/10.17559/TV-20171018100732

[6] Litvin, F. L. \& Fluentes, A. (2004). Gear Geometry and Applied Theory. Cambridge University Press. https://doi.org/10.1017/CBO9780511547126

[7] Radzevich, S., P. (2010). Gear Cutting Tools, Fundamentals of Design and Computation. CRC Press.

[8] Batsch, M., Markowski, T., Legutko, S., \& Krolczyk, G. M. (2018). Measurement and mathematical model of convexoconcave Novikov gear mesh. Measurement, 125, 516-525.

[9] Ratajczyk, E. (2005). Coordinate measuring technique. Warsaw University of Technology Publish House.

[10] Sadilek, M., Fojtik, F., Sadilkova, Z., Kolarik, K., \& Petru, J. (2015). A study of effects of changing the position of the tool axis to the machined surface. Transactions of FAMENA, 39(2), 33-46.

[11] Sadílek, M., Kousal, L., Náprstková, N., Szotkowski, T., \& Hajnyš, J. (2018). The Analysis of Accuracy of Machined Surfaces and Surfaces Roughness after 3axis and 5axis Milling. Manufacturing Technology, 18, 1015-1022.

[12] Härtig, F., Lin, H., Kniel, K., \& Shi, Z. (2013) Laser tracker performance quantification for the measurement of involute profile and helix measurements, Measurement, 46, 28372844. https://doi.org/10.1016/j.measurement.2013.04.037

[13] Gadelmawla, E. S. (2011). Computer vision algorithms for measurement and inspection of spur gears. Measurement, 44 , 1669-1678. https://doi.org/10.1016/..measurement.2011.06.023

[14] Dong-yuan., G, Xi-fan Y., Zhao-tong L., \& Hai-zhi W. Applications of computer vision in measuring total cumulative pitch deviation of a gear. Technical gazette, 24(1), 71-78. https://doi.org/10.17559/TV-20160525162728

[15] Okuyama, E., Kiyono, K., \& Moritoki, H. (1994). Investigation of an optical noncontact gear geometry measurement system: measurement of pitch errors and tooth profiles. Precision Engineering, 16(2), 117-123. https://doi.org/10.1016/0141-6359(94)90196-1

\section{Contact information:}

\section{Piotr BORAL, PhD hab. eng.}

(Corresponding author)

Czestochowa Univertsity of Technology,

Ul. Dabrowskiego 69, 42-201 Czestochowa, Poland

E-mail: piotrek@itm.pcz.pl

\section{Rafał GOŁĘBSKI, PhD eng}

Czestochowa Univertsity of Technology,

Ul. Dabrowskiego 69, 42-201 Częstochowa, Poland

E-mail: rafal@itm.pcz.p

Antun STOIĆ, prof

University of Slavonski Brod,

Mechanical Engineering Faculty in Slavonski Brod

Trg Ivane Brlić Mažuranić 2,

35000 Slavonski Brod, Croatia

E-mail: astoic@unisb.hr 